\title{
Erratum to: Airway Management in Ambulatory Anesthesia
}

\author{
Greta Gormley • Stephen Mannion
}

Published online: 27 September 2014

(C) Springer Science + Business Media New York 2014

\section{Erratum to: Curr Anesthesiol Rep}

DOI 10.1007/s40140-014-0075-4

The original version of this article, published in Current Anesthesiology Reports, contained a misprint in the list of references. In Ref. [9], the name of the principal author, Dr. Sushil P. Ambesh, was mistakenly omitted from the citation. The spelling of "Taiwan" within the title of the journal was also incorrect. This is the correct citation.

\section{References}

9. Ambesh SP, Singh N, Rao PB, Gupta D, Singh PK, Singh U. A combination of modified Mallampati score, thyromental distance, anatomical abnormality, and cervical mobility (M-TAC) predicts difficult laryngoscopy better than Mallampati classification. Acta Anaesthesiol Taiwan. 2013;51(2):58-62.

The online version of the original article can be found under doi:10.1007/s40140-014-0075-4.

G. Gormley · S. Mannion ( $₫)$

Department of Anaesthesiology, South Infirmary, Victoria

University Hospital, Old Blackrock Road, Cork, Ireland

e-mail: mannionstephen@gmail.com

G. Gormley

e-mail: gretagormley@ hotmail.com 